\title{
CORRIGENDUM
}

\section{ATF-2 controls transcription of Maspin and GADD45a genes independently from p53 to suppress mammary tumors}

T Maekawa, Y Sano, T Shinagawa, Z Rahman, T Sakuma, S Nomura, JD Licht and S Ishii

Oncogene (2014) 33, 3618; doi:10.1038/onc.2014.140

Correction to: Oncogene (2008) 27, 1045-1054; doi:10.1038/sj. onc.1210727; published online 13 August 2007

The experiments for Figures $4 \mathrm{e}$ and $5 \mathrm{~d}$ were performed at the same time. In the original figures, some lanes were connected to categorize specific tumor type, and during this process some errors occurred. Now, to clarify the correlation with the

e

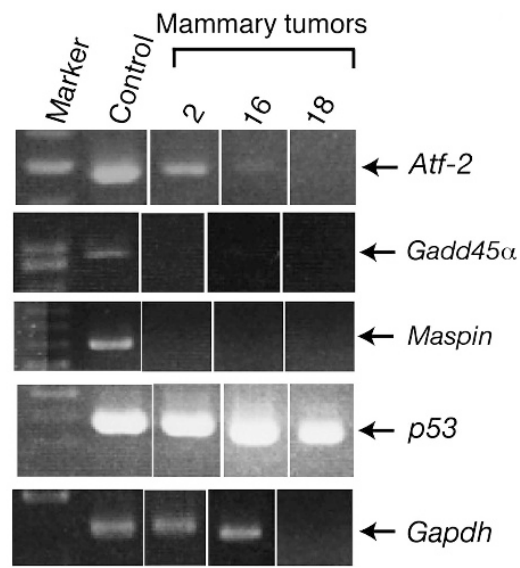

Figure 4.

original data, space has been inserted if the adjacent lane was separated in the original photos. The corrected figures are shown below. The corrected data indicates that Gapdh mRNA level in tumor-18 is low (Fig. 4e), so that a decrease in Atf-2, Gadd45a, and Maspin mRNA level in tumor-18 is not evident. The authors apologize for any confusion this error might have caused.

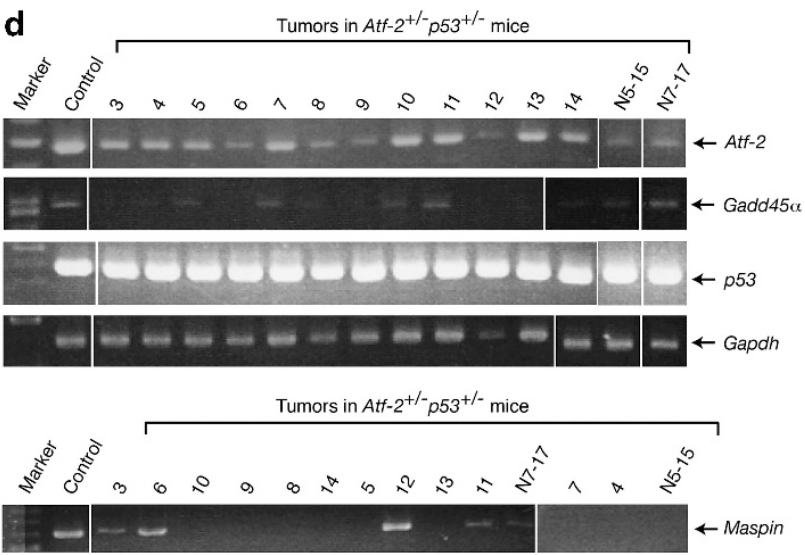

Figure 5. 